\title{
In Defense of Culturally-Specific Organizations: Understanding the Rationale and the Evidence
}

\author{
Ann Curry-Stevens, Jennifer Sita Muthanna \\ School of Social Work, Portland State University, Portland, OR, USA \\ Email: currya@pdx.edu
}

Received 14 January 2016; accepted 21 February 2016; published 24 February 2016

Copyright (C) 2016 by authors and Scientific Research Publishing Inc.

This work is licensed under the Creative Commons Attribution International License (CC BY). http://creativecommons.org/licenses/by/4.0/

\section{(c) (i) Open Access}

\begin{abstract}
Racial disparities abound in human services, with communities of color facing grave impediments to positive progress. Mainstream institutions move painstakingly slowly on reforms-movement too slow to offer this generation prospects for real hope in equity. This paper builds the rationale for expanding funding for culturally-specific organizations, detailing the ways that the literature and the tacit knowledge of culturally-specific organizations improve outcomes for clients and communities of color. The article identifies the service benefits in terms of client outcomes, accountability practices, community benefits, cultural affirmation and inclusion, building community and political capital, and lessening investments in white-centric services. We also identify methods for funding bodies to invest in culturally-specific organizations, and consider the accountability practices that might stimulate mainstream organizations to make gains in racial equity.
\end{abstract}

\section{Keywords}

Culturally-Specific Organizations, Ethnic Agencies, Racial Disparities, Racial Equity, Dangerous Allies

\section{Setting the Context}

As institutions consider how to move forward with the eradication of institutional racism and racial disparities, communities of color and minority ethnic groups are waiting-sometimes patiently and sometimes not. In Multnomah County (in Oregon, USA), the Coalition of Communities of Color, an alliance of over 25 culturallyspecific community based organizations, is pressing for an alternative: equitable funding for culturally-specific organizations in order to improve the service outcomes for communities of color who have been waiting for 
racial equity for generations.

In this region, communities of color have spent the last ten years building an advocacy-based, multi-sector, multi-racial coalition to identify and advance collective interests. In 2003, their organizing and collective voice led to the redirection of approximately $25 \%$ of the County's anti-poverty funds to culturally-specific organizations to meet the needs of children of color. The effort was successful in reaching children of color-as $66 \%$ of the service users within these anti-poverty programs were children of color, compared to less than $20 \%$ before this effort, when outreach had primarily reached white families (Curry-Stevens, Cross-Hemmer, \& Coalition of Communities of Color, 2010). And still, rising poverty and rising disparities within poverty cause grave challenges for the region. In response, the Coalition of Communities of Color has added research to their organizing efforts, and expanded their policy advocacy practices, including creating a policy agenda that has been effectively gaining attention. One of these efforts is to build more support for the provision of culturally specific organizations to deliver services to communities of color.

Data from the Coalition of Communities of Color reports show that, today, the stakes are high. In almost all areas of life, communities of color face deep and, in numerous instances, worsening racial disparities. Research work undertaken in partnership with the School of Social Work at Portland State University (with the lead researcher who is a white academic and the first author of this paper), large disparities have been identified in a total of 28 different institutions and systems, including, for example, income, poverty, public service employment, small business, education, pre-school access, child welfare and much more. Even in remedial interventions such as protected contracting and ESL education, disparities abound (Curry-Stevens, Cross-Hemmer, \& Coalition of Communities of Color, 2010). What this means is that despite advances in civil rights legislation and its protections, and despite the end of segregation and other more overt forms of discrimination and exclusion, communities of color suffer the consequences of racism by living shorter lives, with more ill health, and with much reduced chances of thriving economically, politically and socially. At the same time, white people are more likely to be on the beneficial end of these systems and institutions, with higher graduation rates, access to better employment, with assets and protections that support their wellbeing. When institutions to support individuals and families are studied, we find that white people are more likely to penetrate a positive system (such as higher education or civil service employment) while people of color are more likely to penetrate a negative system (such as the criminal or juvenile justice system or the child welfare system). These inequities thwart communities of color, and the goal of the Coalition of Communities of Color is to eliminate the array of institutional racism that exists and improve the quality of life for people of color.

The goals of this text are five-fold: first, we aim to explain the rationale behind the emphasis that culturallyspecific organizations have for the funding of such services, and build the foundations for such a position, identifying the theory, ideology and experiences that make such organizations a key part of their policy platform. Second, we aim to consolidate the literature, with an emphasis on the research-based writings, in this area. Third, we aim to forward the perspectives of service providers in this field, introducing newer insights into the value of such services which have not yet appeared in other literature. Fourth, we identify the concrete ways in which funders can implement such an approach to service provision. And finally, we suggest needed "next steps" for this field of practice. Throughout the work, we take the opportunity to juxtapose culturally-specific organizations with "mainstream" services, and with workers of color compared with white workers. The differential subject positions of the organizations, the staff, and even the writers of this article can amplify the points we are advancing in this paper.

To understand our contemporary predicament of racial disparities, it is necessary to consider what already has transpired. Feagin and Bennefield (2014) contend that 85\% of US history is comprised of systemic oppression and racism (i.e., genocide, slavery, and segregation). Racism often is defined broadly and imprecisely (Song, 2014). Feagin (2006) and Feagin \& Bennefield (2014) helpfully identifies the major dimensions of US racism: 1) dominant racial hierarchy, 2) comprehensive white racial framing, 3) individual and collective discrimination, 4) social reproduction of racial-material inequalities, and 5) racist institutions integral to white domination of Americans of color. These dimensions of racism have resulted in the unjust material and immaterial gain for whites (over multiple generations) at the expense and systemic exclusion of people of color.

Relations between whites and communities of color have changed dramatically over the generations. Initial encounters were those of annihilation. Next came segregation and "separate but equal" policies. Following the rebellion of the civil rights movement and the dismantling of segregation policies came the advent of assimilation with vestiges of the desirability of the "melting pot" remaining with us today. It is such an approach that is 
echoed in the "one-size-fits-all" approach to services. Next came that of colorblindness that was the advent of liberal whites thinking we were doing people of color a favor by "not noticing" skin color. Experiencing the receiving end of such a gaze is fraught with ignorance and isolation, and ripe with discourse that precludes the possibility of naming racism or white privilege - an approach that leaves institutional racism not even being namable, let alone deconstructed. Next has come the approach of "tolerance" which sets a much too low bar for acceptance and equality. Again consider what it means to receive such a gaze-if one is tolerated, few expectations exist for real inclusion or the sharing of power. The remnants of all these hegemonic approaches remain in US society today. Thomas and Brunsma (2014) contend that some circles are undergoing an epistemological shift whereby racism is constructed as a medical problem. That is, there is a decided shift to remove structural power and replace it with pathology. How might this assuage "white guilt" while reinforcing the demand that people of color deal with and accept the status quo?

Looking at this scan of approaches to racial "difference" emphasizes how deeply mainstream US society has failed communities of color. Simultaneously, we have grown institutions that are ripe with racial disparities. Even when knowing that disparities abound, our interventions are inadequate, leading to the admonishment by Bell and Ridolfi (2008) for our "adoration of the question." The field of disparity reduction has mostly been a dismal failure: disparities have barely budged and in many cases worsened over the last 20 years (Chapin Hall Center for Children, 2009; Rivera, Cotto-Escalera, Desai, Huezo \& Muhammad, 2008; Miller, 2009; US Dept. of Health and Human Services, 2001; US Department of Labor, 2009).

The predominant response today to disparities is that of cultural competency trainings for service providers. While cultural competency can be implemented in far-ranging ways (from its robust roots in the work of Terry Cross, 1991, who implicates community accountability, to the other end which covers minimalist work on crosscultural communications), its current dominant form is one that sees racial identity as issues of difference that need to be navigated with sensitivity - missing that racial identities are not merely issues of difference but rather that they are hierarchically configured manifestations of power (Pon, 2009). To be Latino (for example) is not merely an issue of racial "difference" but rather one infused with inferiority. At the same time, white identity holds markers and systems of access to privilege and its correlated power, whiteness is embedded in superiority and influence. Today, it is possible and in some regions likely, that one will attend trainings in cultural competency and not hear the words "racism" or "white privilege" spoken.

Giving voice to some of the social consequences that might come to mind with raising the emphasis on culturally-specific organizations, we anticipate concerns about what this means for the overall integration ethos that racial progress aims for. Does this direction lead us back to segregation? Absolutely not. Does it mean that the goal of integration has failed? No, because many gains are still in evidence, and here the importance of electing a Black president cannot be understated. But we are up against progress that moves very slowly and sometimes ground is being lost. Quite simply, the risks of leaving another generation to wait while mainstream organizations move too slowly and with too few concrete benefits for communities is not one that can be tolerated any longer. One might also wonder if this approach to human services leaves white workers (and students who are in programs readying themselves for practice) without a role in serving communities of color. We simply ask for the reader to notice the orientation to whiteness that infuses such a question. We have many decades of approaches to human services that have legitimated white workers, through efforts such as "color blindness" and "cultural competency" and even the newest approach, "anti-oppressive practice." All are founded on the assumption that if white workers could just practice more effectively, their efforts will reap benefits for clients and communities of color. What if that supposition is wrong? Perhaps it is an erroneous pathway to take towards racial equity, and perhaps we still have such deep disparities in human services because we are working from a paradigm that largely invalidates the need for culturally-specific organizations to work with communities of color. We do not provide our best insights on this question until the end of this text. We encourage readers to bracket defensive positions such as these until you have read the evidence and conceptual foundations we establish in this text. At the close of the article, we will return and provide our best synthesis of an answer to the question, "what does such an approach mean for White workers?"

\section{Positionalities of the Authors}

In the interest of transparency, some acknowledgements must be made. The authors of this paper are a white social work academic and a brown social work PhD student. We encounter racism and white privilege every day, 
and in diametrically opposing ways. While based in the same institution, our white academic enters such spaces as an insider, with daily affirmation of her value to the school, and where her role as an instructor is confirmed by the deference her students provide, and where her scholarship receives regular accolades. Our brown PhD student enters our building as, generally, not belonging, and faces challenge as a classroom instructor, with students fairly routinely challenging her value as an instructor-a dynamic that is infused with racism. As a student, she suffers through texts that were mostly written by white authors for white students (not overtly, but rather by default for the invisibility of perspectives of people of color is largely absent from all academic narratives in social work). She suffers through instructors, the majority of whom are largely incapable of responding to challenges about white dominance and how it plays out in scholarship and in the classroom. She must be ever vigilant to not exhaust the goodwill of or investment by those instructors who understand or "get" these challenges. Finding a place of legitimacy to stand has needed to be a priority for our author of color. She has had to establish it for herself, as opposed to having the advantage of white privilege establish her more automatically and discursively.

The failings of the social work profession to more inclusively advance scholarship in this area leaves our white author with a moral compulsion to press the profession to explore more rigorous solutions to inclusive anti-racist practices and policies, and she is committed to pushing for interventions that will more effectively serve communities of color. Our brown student is stepping into the space created by such shifted discourse, and is building an investment in exploring the benefits of culturally specific organizations, in a current GRA appointment, and with an emerging interest in this work in the coming years. We aim to fill a gap in the literature with this article, believing it holds potential to reconfigure both the human service landscape, but also the social work profession and social work classroom, as it may legitimate an anti-colonial discourse in how services are provided and how students of color hold unique and distinct roles in the leadership of human services.

Ontologically, we recognize that racism exists and that it is a pervasive force. Communities of color tell how racism is deeply entrenched and we respect their truths and knowledge. They express disappointment that progress in attending to disparities in access, opportunities, and resources is expected to be at a pace that is palatable to white power-holders. Also, despite living in a country with a Black US President, it is evident that we do not live in a "post-racial" society. The construct of race is powerful and is deeply reflective of power, privilege, and history. The mere election of a Black President cannot subvert or alleviate the impact of our long racialized history. Additionally, we repudiate "reverse racism." A systemic and post-structural analysis of racism understands that this is fundamentally impossible. It requires power (social, economic, and political) and is institutional in nature. Finally, we unapologetically use emotive and evocative language in this piece. The impact of racism is real and troubling. We have squandered too many opportunities to redress these disparities-and we hope for this article to serve as a call to action.

\section{Literature Review}

The literature in this area is thin, yet illuminates some promising features of culturally-specific organizations, known sometimes in the literature as "ethnic agencies" (Holley, 2003; Iglehart \& Becerra, 1996), or in Canada as "ethno-cultural organizations" (Hansson, Tuck, Lurie, \& McKenzie, 2010). The literature review is organized in the following way: beginning with the benefits that have been identified as accruing to clients, then moving to the accountability practices, and then moving into community benefits. In the majority of the resources used, the findings are research-based, and in a minority, they are conceptually rooted. We then conclude the section identifying three features that have been voiced by members of the Coalition of Communities of Color, but that have yet to appear in the literature.

\subsection{Client Outcomes}

Three large comparative studies similarly find that culturally-specific services provide better outcomes for clients of color in the areas of being less likely to drop out of services, being more willing to return for service provision, using services more fully and being engaged in services for longer periods of time (Hohman \& Galt, 2001; Takeuchi, Sue, \& Yeh, 1995; Yeh, Takeuchi, \& Sue, 1994). Dimensions of such services are understood to be more holistic, focusing less on the treatment of individual "pathologies" and more likely to understand racism as central to the experiences of people of color (Takeuchi, Sue, \& Yeh, 1995; Uttal, 2006). Furthermore, Uttal (2006) adds that cultural-specificity helps clients avoid sticking out as "other" and thus provides a culture 
of inclusion for clients of color. Also documented are that culturally-specific organizations have emerged to address the underuse of services by immigrants and communities of color (Goh, Low, \& Brodaty, 2010). The work of Delgado (1997) emphasizes that racial alignment among service providers and clients allows for issues of mistrust and fear that exists in a non-racially matched context to be bypassed.

Delving deeper into why mainstream services are less likely to achieve positive outcomes takes us into the notion of the client-worker "match." The research illustrates that a "match" between the identity of workers and clients has a positive impact on client outcomes. This match creates fewer clients departing prematurely from services, making better use of services and improving mental health outcomes and life skills functioning, plus being retained in services for longer periods of time (Hohman \& Galt, 2001). Additional research emphasizes their retention in services and staying involved for longer periods of time. More research on the importance of this "match" shows that a history of hostile relationships between the client and worker serves to contaminate the work with tension and mistrust (Yamamoto, Silva, Justice, Chang, \& Leong, 1993). Colonizer and colonized histories that demark most white encounters with clients of color are prone for distrustful relationships that create an additional barrier to service effectiveness, and also to service access, once complaints filter through communities of color about such shortcomings.

Moving beyond the issue of the "match," many instruments used by mainstream health and social services are culturally inappropriate (Dana, 1993). Most tools rely on cultural norms that are from white society and inappropriately used among communities of color (such as excessive valuation of independence). Research has demonstrated that many tools do not have cross-cultural validity (Paniagua, 2005). One not-uncommon example is that experiences of racism, when retold to the white practitioner, are likely to be perceived as unreasonable feelings of persecution or even self-grandiose beliefs. This creates a bias in the tools that leads to over-diagnosis of people of color. Practitioners typically do not understand the cultural and racial dimensions to these variables, and are more likely to show up as mental health illnesses. Failure to understand coping strategies serves to create over-diagnosis of communities of color. Spiritual beliefs and use of traditional healers are not infrequently mistaken by white service providers as evidence of psychopathology (US Department of Health \& Human Services, 1999).

Language accessibility deepens the over-diagnosis problem. When clients are diagnosed in a language in which they are not fluent, they are more likely to be given diagnoses that suggests they are more mentally ill than is the fact. The term for this is "over-diagnosis." When clients are not interviewed in their own language, they are likely to have given more severe psychiatric diagnoses, and are less likely to comply with the therapist's recommendations, and more likely to drop out of treatment (Seijo, Gomez, \& Freidenberg, 1991).

Culturally-specific organizations are also more likely to emphasize the larger context that explains the distress of individuals. Such services have less focus on individual "pathologies" to explain distress and are more likely to understand distress through challenges developed through racism, discrimination, unfair treatment and damaging ideas about communities and people of color. In addition, communities of color prefer interventions that provide tangible supports to address immediate problems (Boyd-Franklin, 1989; Walker \& LaDue, 1986). The importance not only of workers sharing backgrounds and identities (with additional emphasis from Rivera \& Erlich, 2001 and from Rossiter, 2000), but also of the organization to be "owned" by the community it serves cannot be understated. The contributions from Gutierrez \& Lewis (1999) amplify the importance of shared identities as a feature of promoting understanding and affirmation of the structural causes of individual distress. The field of education has focused more expansively on the benefits to students to be taught by a teacher of color: When students of color are taught by educators who share their race, there is a positive impact on test scores for students of color (Clewell et al., 2005; Dee, 2004; Eddy \& Easton-Brooks, 2011) reducing the achievement gap (Easton-Brooks et al., 2010), and improving reading acquisition (Clewell et al., 2005).

A final dimension of this research shows that even the context of administering tests serves to influence outcomes. When whites administer IQ tests to African Americans, their test scores fall (Jenkins \& Ramsay, 1995, as cited in Paniagua, 2005). In addition, interviewing conducted outside one's native language increases errors and diagnostic labels are accentuated (Marcos, 1976, as cited in Paniagua, 2005). While this serves as greater impetus for expanding culturally-specific organizations for communities of color, it also serves to punctuate the possibility that administration of surveys and census forms might be inappropriately conducted by whites or by those who do not share the identity of the person being surveyed. By extension, this should make researchers wonder if people of color are more likely to self-identify their heritage accurately if surveys and other demographic collection forms are better and more accurately administered in a culturally-relevant context. 
In summary, while the literature is thin, social workers and other health, education and human service providers need to consider how the benefits of services is limited by the fact they are occurring in a mainstream context. Beyond the appropriateness question, mainstream providers (and those who prepare them for practice, such as faculty in social work programs), need to be aware of the potential inaccuracies (and by extension, injury) that occur when practitioners work outside of their own cultural context, and when distress holds potential to be pathologized instead of understood in the context of broader systems of injustice and discrimination. Iglehart and Becerra (1996 \& 2007) emphasize that mainstream services have broadly and widely failed communities of color through neglect and through issues related to the shortcomings of white service providers in providing culturally-sensitive practice.

\subsection{Accountability Practices and Service User Voice}

Among the more than 25 organizations that are members of the Coalition, each adheres to accountability practices whereby the majority of their Board of Directors are community members from the specific racial and/or cultural group being served, making for organizations that are durably and organically accountable to and responsive to the changing needs of their communities. Prior research emphasizes the importance of accountability to the community (sometimes operationalized as to "clients" or "consumers") to ensure high quality programs. Known as the field of "user involvement in service delivery," the research illustrates revisions needed to epistemological valuing and the necessity of situating knowledge and expertise in the service user, to supplement, modify or replace the convention of situating expert knowledge in the hands of staff and administrators. Increasingly, the post-modern critique of the divide of subject/object to correlate with service provider/service user has called us to problematize expert knowledge. Today the field of human services holds a much more narrow appreciation of expert knowledge, particularly when this knowledge is the result of academically-derived credentials as opposed to the situated and subjective experiential knowledge of service users and community members. While the dominant discourse remains largely intact that service user knowledges are invalid or contaminated, such knowledges need to be granted primacy as they are derived from being service users and subjects of services (Beresford, 2000). This position is most true when considering communities of identity such as communities of color. In essence, the supposition is that the experience of racism as an African American or a Latino provides one with a much more accurate understanding of the utility of human services to address distress that has likely been caused by racism.

Growing out of dissatisfaction with paternalist and tokenizing involvement of service users in human services (Beresford, 2000), service users have created both claims to voice and influence in service delivery and have also built social movements to advance more enfranchisement struggles for awareness, acceptance and respect, and have also built political power. Examples include the Mad Pride movement, and the persons with disabilities movement. The mantra, "nothing about us without us" encapsulates these movements and their goals-this is, not coincidentally - one of the key commitments of the Coalition research partnership with Portland State University to ensure that both philosophy and practice centers accountability to communities of color, and furthermore that ensures knowledge and expertise is situated in communities of color.

One related field of research is that of "youth voice" which operates outside of a racial context, but this research amplifies the importance of involving service users and community members in the leadership of the organization. One study by Zeldin (2000) identified that “... in many organizations, the young people become the keepers of the vision. They are the ones who focus on the mission” (p. 5) and that they assist organizations (when they participate in governance structures) to make effective decisions. A youth voice study with runaway and homeless youth revealed that the highest priority for improving services was to expand the role of clients in services, articulated as “youth voice” (Schweitzer, 2011) in how services are designed, implemented and evaluated. Early research on the role of educational leaders in enabling student voice has been found important for closing the achievement gap (Mitra, Serriere, \& Stoicovy, 2012). Research on how to foster student voice shows it is best supported by school's organizational reforms, larger institutional reforms and pedagogical shifts (Skrtic, Sailor, \& Gee, 1996). While the field of service user involvement is an avenue for mainstream organizations to ensure that community needs hold influence in the organization-and thus is more about mainstream organizations having access to legitimacy-building practices - the field reminds us that community members must ultimately be arbiters of the value of a service. As consumers of what the UK calls "social care” (Beresford, 2000; Butcher, 2008), the community must find a resource or a system useful in order for it to be legitimate. 
Within culturally-specific organizations, accountability to the community exists throughout delivery, from governance structures where community members typically hold the majority of positions on the Board of Directors, to holding top staffing positions, and to providing important pathways for community members to become staff. The staffing structure of culturally specific organizations ensures that there are ongoing commitments to ensure that the voice and experiences of the community are infused in the organization. This also means that community members are involved in advocacy practice through in consultations, and in advisory and steering committees. Such measures are generally missing in mainstream organizations, except in more tokenized roles.

\subsection{Community Outcomes: Community Development and Systemic Advocacy}

The ways some of the community benefits have been measured include the following: hiring staff from the community and those who speak their language, include community practices in supporting the individual, engage in community development to increase cultural pride, decrease isolation and exclusion, encourage cultural consciousness, build power, address issues of racism, locate services in the community and offer holistic programming (Gillam, 2009; Holley 2003; Uttal, 2006). They are also more likely than mainstream organizations to provide such benefits.

Gillam's (2009) work further describes characteristics of culturally-specific organizations to rely on collaboration with service users to design services, resulting in higher satisfaction with such services. Typically, the community has been involved in creating the service, helping to design its elements and being involved in correlated activities. While this is frequently the way that most service organizations originally developed, most have drifted far away from such organic, community-accountable roots. Mainstream organizations have become "professionalized" and service providers and administrators expect to be making decisions about how organizations should grow, what should be offered, and how they should be evaluated (McKnight, 1995; Margolin, 1997).

We also know from the literature (Gillam, 2009; Holley, 2003) and directly from the experiences of local culturally-specific service providers that advocacy practices are a robust dimension of services, both in one-to-one individual advocacy to help individuals and families gain needed supports, but also for advocacy for institutional reforms such as pressing school districts to hire more teachers of color, for child welfare to recruit more foster families of color, or for the passage of immigration reforms to better sustain families and reduce fears of deportation. All are examples of local advocacy practices being addressed by culturally-specific organizations.

We now turn to detail, in the next three sections, additional elements of culturally-specific organizations that have emerged in dialogues with the members of the Coalition of Communities of Color and the tacit learning we have collaboratively done in considering the assets of their organizations.

\subsection{Cultural Affirmation and Inclusion as Communities of Color Are "Insiders" (Instead of "Outsiders" to the Organization}

In Multnomah County, as noted earlier, racial disparities abound. One school board (the County's largest) Portland Public School holds a graduation rate for Native American youth at 36.3\% and for African American youth at $45.8 \%$, while that of white youth is $61.5 \%$. As a result of these deep failures in educating youth of color, these two communities have developed their own culturally-specific schools: the Native American Youth and Family Centre (NAYA) Early College Academy and the SEI Academy. The graduation rates of these two culturallyspecific schools are $88 \%$ and $98 \%$ respectively (Curry-Stevens, Cross-Hemmer, \& Coalition of Communities of Color, 2010).

What accounts for the difference? Dialogues among communities of color suggest that the community believes that a key difference is that these youth enter the doors as insiders instead of outsiders. In spaces where their culture predominates, they are welcomed into spaces that affirm their identity, that are staffed by people who look like them and share their history. Entering such organizations result in having one's culture and identity validated, rather than diminished as in conventional services. In education, students have a curriculum that reflects their culture, receive education in a culturally-appropriate manner where there is prideful recognition of the community's history and accurate naming of the dynamics of racism, colonization and US imperialism that has harmed the community. In health care, patients have their cultural beliefs and practices understood and 
treated as assets instead of oddities. In human services, cultural norms are cherished and their contributions to the community honored instead of abhorred.

Additionally, the daily aggressions created by being a person of color in white society (as powerfully detailed by Sue, 2010) are minimized while they are in such spaces, affording students of color a respite from racism (Curry-Stevens, Cross-Hemmer, \& Coalition of Communities of Color, 2010; Gillam, 2009; Takeuchi, Sue, \& Yeh, 1995).

We also stretch this benefit across the community. When, for example, the Native American community operates a school for its own youth, the success of these youth benefits the community at large and the investments are those that flow from a shared identity (Coalition of Communities of Color, 2010). Consider on the other hand what investments exist for mainstream service providers: the investments for white people in the success of communities of color are typically fleeting or as one Coalition member states, "the flavor of the month." We believe that the benefits can come from the fact that clients, staff and those who govern the organization have tied futures, as opposed to connections that are less durable, marked by distance and the absence of shared kinship: if the school system (for example) does not work for my children, my neighbor's children and my hairdresser's children, then my objection, my anger and my response will be immediate, deeply rooted and profound. If the school system does not work for people I do not know nor who I interact with in daily life, then my upset will be muted and fleeting: not the sort of reaction that will catalyze real reforms.

\subsection{Building Community Capital, That in Turn Can Become Political Capital}

We perceive that culturally-specific service organizations are creating additional impacts on the communities in which they are based (as geographic and/or identify-based communities). They improve local employment among communities of color that typically face serious employment disparities. Alongside these employment opportunities, they foster leadership development in both volunteer roles and paid staff roles that in turn builds a form of "community capital," as a form of "social capital" that can be drawn upon both now and into the future (Bourdieu, 1985). Such capital grows as community members develop their own solutions to issues and build capacities to tackle future issues. So too local leaders are developed among Board members, advisors, staff and volunteers. At the same time, local knowledges grow and flourish as the community builds expertise, influence and a correlated positive reputation for meeting community needs. Through such activities, there are ripple effects, achieving what Beresford (2000) cites as "recognition [being] given to the validity of the subjective knowledges, analyses and perspectives" of community members (p. 501). The investments in communities of color to develop and expand culturally-specific organizations also becomes a form of economic capital as both a place of employment (essential as income, unemployment and occupational segregation are deeply disparate for communities of color) and as an anchor for future economic growth. Such investments serve to stabilize a community. We also perceive that as these human assets develop, larger regional economic benefits are anticipated (although not yet confirmed through the research).

\subsection{Differential Benefits to Whites Makes Losses to Communities of Color More Significant}

Adding further injury to the fact that mainstream services are neglecting to provide many of the individual, community and social benefits that are associated with culturally-specific organizations, there is a real possibility that institutional disparities and inadequacies might even work to benefit White folk-by allowing the better grades and scholarships to be available to white youth, or the better jobs and promotions to be available to whites. In the justice system, imprisoning more people of color lets whites retain both an ethos of superiority and real democratic power-the impact of removing thousands from voting entitlements keeps elected power whiter (Alexander, 2010). By extension, white people can actually be invested in sustaining inequities because the benefits of privilege are retained instead of shared. This is a manifestation of the colonial residue that exists in the human service network, and why culturally-specific organizations hold the potential to be anti-colonial service providers. Communities of color must, therefore, gain control over services on which they depend.

In addition to these benefits, culturally-specific organizations are positioned to enact commitments to racial equity and to expanding notions of equality, democracy and community wellbeing (Coalition of Communities of Color, 2010; Gillam, 2009). As such services provide for communities of color to extract themselves from relations with mainstream services which have largely failed communities of color, they are ideologically valid by 
any form of human rights and social justice objective. Tracking the history of some of these failures along with an analysis of the principles which have catalyzed such a rupture in trust provides us with an alternative set of principles for moving forward with culturally-specific alternatives.

\section{Synthesis of Mainstream and Culturally-Specific Organizations}

Summarizing the positive benefits of culturally-specific organizations, we find that they hold the potential to provide vastly improved services to people of color and simultaneously become an important form of social and economic capital, with benefits stretching across the community. In an era of profound racial inequities, such investments must not be seen as marginal. Table 1 provides a synthesis of these features.

\section{More Complex Considerations of Racial Equity}

Notice, importantly, that the cultural competency movement implicitly continues the "one-size-fits-all” approach to services. While it aims to make mainstream services a more positive experience for communities of color, it maintains arrogance for suggesting that if mainstream service providers can simply become more skilled, then communities of color will have their needs met. Mainstream service providers have had their (our) chance and blown it. An analysis of why we have blown it is essential to narrowing the chance for continuing and repeating these errors. The primary cause is that whites are "dangerous allies" (Lopes \& Thomas, 2006: p. 225) in movements towards racial equity. They are dangerous allies for a number of reasons: their commitments to racial equity are less durable than those of people of color, we do not live intimately with the results of inadequate responses to inequities and nor do we have an internal compass that always guides us towards action instead of inaction.

While the ally model (Bishop, 2002) is still valid for providing concrete roles and practices for people with privileged identities in work with marginalized communities, it would be a mistake to overly idealize the contributions of allies. Here is a profile of the mistakes made by allies: first, allies define themselves as such after building an awareness of injustice. Allies do not, however, necessarily know what action is needed, nor are we necessarily likely even to act. Awareness, while an important precursor to action, is not a guarantee of action. Second, allies typically shift their identity away from being "white" to being a "white ally." While an important

Table 1. Synthesis of engagement between communities of color and service providers.

\begin{tabular}{|c|c|c|}
\hline \multirow{2}{*}{ Element } & \multicolumn{2}{|c|}{ Type of Organization } \\
\hline & Mainstream Organizations & Culturally-Specific Organizations \\
\hline 1) Primary experience & Outsider & Insider \\
\hline 2) Own culture & Not affirmed or possibly denied or demeaned & Centered and affirmed \\
\hline $\begin{array}{l}\text { 3) Commitment to the } \\
\text { success of people of color }\end{array}$ & $\begin{array}{l}\text { An afterthought at best, and active disinterest } \\
\text { or devalued (at worst), and likely temporary, } \\
\text { as in "flavor of the month" }\end{array}$ & $\begin{array}{l}\text { Durable and deeply rooted across } \\
\text { the organization }\end{array}$ \\
\hline 4) Accountability & Not to the community & To specific communities of color \\
\hline $\begin{array}{l}\text { 5) General Societal } \\
\text { Discourse }\end{array}$ & $\begin{array}{l}\text { Generally dominant discourse with } \\
\text { demonstrated histories of continuing } \\
\text { racial disparities in service outcomes }\end{array}$ & $\begin{array}{c}\text { Typically resistive, with potential for anti-colonial } \\
\text { discourses to be affirmed at a client and organizational } \\
\text { level, and stretching to societal influence }\end{array}$ \\
\hline 6) Assessments & $\begin{array}{l}\text { Keep problems individualized and tending } \\
\text { towards pathologizing }\end{array}$ & $\begin{array}{l}\text { Problems are socialized, contextualized and issues of } \\
\text { racism and discrimination will be included prominently }\end{array}$ \\
\hline 7) Interventions & $\begin{array}{l}\text { Not culturally-relevant and likely limited to } \\
\text { individual and family interventions }\end{array}$ & $\begin{array}{l}\text { Culturally relevant and likely to include community } \\
\text { development and systemic and individual advocacy }\end{array}$ \\
\hline 8) Epistemology & $\begin{array}{c}\text { Likely reliant on external sources of expertise } \\
\text { and treating community of color as having } \\
\text { invalid knowledge }\end{array}$ & $\begin{array}{l}\text { Community members as experts with } \\
\text { subjective knowledges affirmed }\end{array}$ \\
\hline 9) Design influence & $\begin{array}{l}\text { Minimal and a latter consideration with } \\
\text { occasional consultations likely }\end{array}$ & Community members deeply involved \\
\hline
\end{tabular}


and valuable commitment might underpin this new identity, both Glass (2008) and Thompson (2008) identify that such reworked identities tend to diminish the role of allies as complicit and implicated in relations of domination. In essence, the argument is such: "because I am an ally, I no longer am part of the problem-I am part of the solution." It is this stance of "exceptionality" that lets white allies believe themselves to be reliable and durable allies. Third, anticipating white allies to be significant participants in reform efforts is ill advised because such roles require them to "rock the boat." Dominant characteristics such as patience and slow incremental changes are valued inside organizations but more bold action is often needed. When organizations want slow incremental change, allies will be prone to compliance and thereby a disappointment to communities of color who are relying on more significant action for change.

It is impatience and urgency for real reforms today that must have primacy in both racial equity movements and in culturally-specific alternatives. We must notice that whites fall short on these criteria-their white children are not waiting for change, as the world already works quite well for them. Notice whose lives are sacrificed while US society and mainstream services have erred and dallied with these "solutions" to difference. It is not the white child-it is the children of parents of color. It is not the white child whose future is compromised nor who cannot make hope real. Rather, families of color have their futures put on hold, being expected to wait while reforms take place (or do not take place).

The white author in this study has previously written about her unreliability as a white ally (Curry-Stevens, 2010). Instead, her commitments are those generated though empathy, outrage at injustice, the values of equity which infuse how she understands her work-but they pale in comparison with the investments of people of color in racial equity work. Ultimately, despite all the good intentions she has in action towards racial equity, she should not be relied upon to act. Her white identity, her ongoing implicated-ness in racism and white privilege, her investments in her own employability and the absence of being hardwired to resist oppression and privilege that combine together to make me a dangerous ally. Extending this analysis to other whites and to mainstream institutions posits that white allies cannot be entrusted with rapid enough movement towards racial equity. The futures of families and children of color are too important to dally any longer, even when there is a growing community of white allies currently eager to make change.

While the white author's analysis troubles the role of equity allies, it leaves our brown author wanting. As a woman of color, she wants to believe that white allies will have the courage to act...and that they will use their power to destabilize systems of oppression in a timely or accelerated manner. She wants to believe that, should a white person earn the title of "ally," it is deserved. She wants to believe that, while allies will invariably make mistakes, they will remain committed to reflexive action. Racial unrest has always been present in this nation, but movements like Black Lives Matter and university divestment campaigns magnify our understanding of present day systemic racial inequities. This is an unwelcome unveiling for those who are complacent about such disparities or, worse, deny the existence of such disparities. The creation of reactive (or dismissive) movements (such as All Lives Matter or Blue Lives Matter) only serve to silence or attack the experiences of communities of color. Yes, communities of color are deeply invested in racial equity work; however, it is (as it always has been) dangerous work. The risks (to one's personal safety, job security, or social standing) are real. For generations, communities of color have been sacrificed, enslaved, and oppressed in order to create and maintain systems of white supremacy. Therefore, while it makes sense to ask communities of color to spearhead movements toward racial equity, there must be a role for white allies and mainstream institutions. They must be called to account....and to atone.

We think there are ways that the divergence in these assessments of the field can be bridged. The concerns are tied to that of accountability that needs to be held both internally and externally for mainstream organizations. Implicitly, these issues are tied to the prognosis for white practitioners and mainstream organizations to uphold a socially just and anti-oppressive practice with communities of color. While this is the fruit for another article, resolution is tied to the pragmatics of accountability for outcomes that benefit workers, communities and clients of color. Mainstream institutions need to figure out how to enact this commitment, as do individual practitioners and the higher education institutions that prepare them for practice. It is again, a rationale for why culturallyspecific organizations need to lay greater claim to funding at this point in time.

\section{Moving Forward}

Improving funding for culturally-specific organizations can occur through dedicated funds or in culturally-spe- 
cific "set-asides" within a larger fund. The first reflects a more robust commitment than the second, and allows for development of the strategy more holistically as the entire fund can be overseen by expertise in the field (including, of course, predominant leadership by people of color). One example is the Convergence Partnership for Healthy Eating and Active Living implemented in 2010 by the Northwest Health Foundation. The lead applicant was required to be a culturally-specific organization. Another example was through Meyer Memorial Trust which emphasized that the lead was to be culturally-specific but make a partnership also possible, but stipulated that the partnership needed to ensure that the culturally-specific organization would share the resources, endorse the application, be invited in non-tokenistic long-terms ways to partner, and to be able to direct the activities of the grant. The second creates specific grant streams within a broader fund for culturally-specific organizations, tying the level of funding to need, such as local anti-poverty programs allocating funds on the basis of the racial identifies of the portion of children in poverty.

A final caution in allocation decisions: the conventional granting practices need to be troubled. Funding decisions typically value prior funding history, pre-existing relationships between funders and grantees, the ability to evaluate programs, high-stature recommendation letters and low cost competitive bids. All these factors serve to reinforce the conventional funding patterns and preference for larger mainstream institutions. Serious commitments to the needs of communities of color simultaneously involves examining decision making practices and discourses — and reworking them to ensure equity in access to funds.

We believe that this article synthesizes the research basis to support culturally-specific organizations to lay greater claim to grant funds to reach and serve communities of color. We simultaneously recognize the need for expanded research and evaluation of culturally-specific organizations so that we can continue to document their success and challenges. The innovation and potential that is offered by such organizations, along with the emergent research base, is encouraging. We believe that there will be more positive results articulated as more research is conducted. It is relatively rare that research on entire organizations is conducted, although case study research holds potential to reveal the comparative benefits of culturally-specific organizations. Investing in such research is important.

\section{Final Thoughts}

The policy agenda emerging from the Coalition of Communities of Color reports gives priority to ending the "wait a little longer" response and makes more urgent the need for reforms. What is available now to communities of color while institutions take their time to move painstakingly slowly towards equity? The core answer? Culturally-specific organizations that are "owned" by the community, accountable to the community, led by members of the community and that respond holistically to the needs of the community. Further definitions of such services include that the majority of service users are from a particular community of color, that the organization's environment is culturally-focused and identified as such by its members, that the staff, board and leadership reflects the community that is services, and that the organization has a track record of successful community engagement and involvement with the community being served (Coalition of Communities of Color, 2010).

As promised, we close by returning to the consideration of "what about white workers and/or students?" We simply say that the social work profession (alongside other health, social, and educational service professions) needs to tolerate the possibility that white centrality and choice to legitimately practice might be narrowed in this approach to practice. We need to de-center whiteness and be able to hold a stance of ambiguity over the role for white practitioners. Simultaneously, we need to center the roles for workers of color. Very little exists in the field for such practitioners; their assets continue to be overlooked if we eclipse their work with concerns for white workers.

At the same time, the field needs to amplify the work being done by mainstream organizations on racial equity: expectations for internal and external progress are essential. We believe the effective design and deployment of accountability structures and practices hold the key to ensuring real progress is made.

\section{References}

Alexander, M. (2010). The New Jim Crow: Mass Incarceration in the Age of Colorblindness. New York: The New Press.

Bell, J. \&Ridolfi, L. (2008). Adoration of the Question: Reflections on the Failure to Reduce Racial \& Ethnic Disparities in the Juvenile Justice System. San Francisco, CA: W. Haywood Burns Institute. 
Beresford, P. (2000). Service Users' Knowledges and Social Work Theory: Conflict or Collaboration? British Journal of Social Work, 30, 489-503. http://dx.doi.org/10.1093/bjsw/30.4.489

Bishop, A. (2002). Becoming an Ally: Breaking the Cycle of Oppression. Halifax, Nova Scotia: Fernwood.

Bourdieu, P. (1985). The Forms of Capital. In J. Richardson (Ed.), Handbook of Theory and Research for the Sociology of Education (pp. 241-258). New York: Greenwood.

Boyd-Franklin, N. (1989). Black Families in Therapy: A Multisystem Approach. New York: Guilford.

Butcher, H. (2008). Service User Involvement in Cancer Care: Policy, Principles, Practice. London: National Cancer Action Team.

Chapin Hall Center for Children (2009). Understanding Racial and Ethnic Disparity in Child Welfare and Juvenile Justice. Chicago, IL: Chapin Hall Center for Children at the University of Chicago.

Clewell, B. C., Puma, M. J., \& McKay, S. A. (2005). Does It Matter If My Teacher Looks Like Me? The Impact of Teacher Race and Ethnicity on Student Academic Achievement. Paper presented at Annual Meeting of the American Educational Research Association, Montreal, Canada.

Coalition of Communities of Color (2010). Multnomah County's Philosophy and Implementation of Culturally Specific Services. In A. Curry-Stevens (Ed.), Cross-Hemmer \& Coalition of Communities of Color's Communities of Color in Multnomah County: An Unsettling Profile (pp. 137-139). Portland, OR: Portland State University.

Cross, T. (1991). Organizational Self-Study on Cultural Competence for Agencies Addressing Child Abuse and Neglect. Portland, OR: Northwest Indian Child Welfare Association, Inc.

Curry-Stevens, A. (2010). Journeying towards Humility: Complexities in Advancing Pedagogy for the Privileged. Reflections: Narratives of Professional Helping, 16, 61-72.

Curry-Stevens, A., Cross-Hemmer, A., \& Coalition of Communities of Color (2010). Communities of Color in Multnomah County: An Unsettling Profile. Portland, OR: Portland State University.

Dana, R. (1993). Multicultural Assessment Perspectives for Professional Psychiatry. Boston, MA: Allyn \& Bacon.

Dee, T. S. (2004). Teachers, Race, and Student Achievement in a Randomized Experiment. Review of Economics and Statistics, 86, 195-210. http://dx.doi.org/10.1162/003465304323023750

Delgado, G. (1997). Beyond the Politics of Place. Berkeley, CA: Chardon Press.

Eddy, C., \& Easton-Brooks, D. (2011). Ethnic Matching, School Placement, and Mathematics Achievement of African American Students from Kindergarten through Fifth Grade. Urban Education, 46, 1280-1299.

http://dx.doi.org/10.1177/0042085911413149

Feagin, J. (2006). Systemic Racism: A Theory of Oppression. New York: Routledge.

Feagin, J., \& Bennefield, Z. (2014). Systemic Racism and US Healthcare. Social Science \& Medicine, 103, 7-14. http://dx.doi.org/10.1016/j.socscimed.2013.09.006

Gillam, T. (2009). Improving Services to African American Survivors from IPV: From the Voices of Recipients of Culturally Specific Services. Violence against Women, 15, 57-80. http://dx.doi.org/10.1177/1077801208328375

Glass, R. (2008). Staying Hopeful. In M. Pollock (Ed.), Everyday Anti-Racism: Getting Real about Race in School (pp. 337-340). New York: The New Press.

Goh, I., Low, L., \& Brodaty, H. (2010). Levels and Rates of Depression among Chinese People Living in Chinese EthnoSpecific and Mainstream Residential Care in Sydney. International Psychogeriatrics, 22, 237-245. http://dx.doi.org/10.1017/S104161020999069X

Gutierrez, L., \& Lewis, E. (1999). Empowering Women of Color. New York: Columbia University Press.

Hansson, E., Tuck, A., Lurie, S., \& McKenzie, K., for the Task Group of the Services Systems Advisory Committee, Mental Health Commission of Canada (2010). Improving Mental Health Services for Immigrant, Refugee, Ethno-Cultural and Racialized Groups: Issues and Options for Service Improvement.

Hohman, M., \& Galt, D. (2001). Latinas in Treatment: Comparisons of Residents in a Culturally Specific Recovery Home with Residents in a Non-Specific Recovery Home. Journal of Ethnic \& Cultural Diversity in Social Work, 9, 93-109. http://dx.doi.org/10.1300/J051v09n03_05

Holley, L. (2003). Emerging Ethnic Agencies: Building Capacity to Build Community. Journal of Community Practice, 11, 39-57. http://dx.doi.org/10.1300/J125v11n04_03

Iglehart, A., \& Becerra, R. M. (1996). Social Work and the Ethnic Agency: A History of Neglect. Journal of Multicultural Social Work, 4, 1-20. http://dx.doi.org/10.1300/J285v04n01 01

Iglehart, A., \& Becerra, R. M. (2007). Ethnic Sensitive Practice: Contradictions and Recommendations. Journal of Ethnic and Cultural Diversity in Social Work, 16, 43-63. http://dx.doi.org/10.1300/J051v16n03_04 
Lopes, T., \& Thomas, B. (2006). Dancing on Live Embers: Challenging Racism in Organizations. Toronto, ON: Between the Lines.

Marcos, L. (1976). Bilinguals in Psychotherapy: Language as an Emotional Barrier. American Journal of Psychotherapy, 30, 552-560.

Margolin, L. (1997). Under the Cover of Kindness: The Invention of Social Work. Charlottesville, VA: University Press of Virginia.

McKnight, J. (1995). The Careless Society: Community and Its Counterfeits. New York: Basic Books.

Miller, J. (2009). The Real Unemployment Rate Hits a 68-Year High. Dollars \& Sense, July-August, 29-30.

Mitra, D., Serriere, S., \& Stoicovy, D. (2012). The Role of Leaders in Enabling Student Voice. Management in Education, 26, 104-112. http://dx.doi.org/10.1177/0892020612445678

Paniagua, F. (2005). Assessing and Treating Culturally Diverse Clients: A Practical Guide. Thousand Oaks, CA: Sage. http://dx.doi.org/10.4135/9781483329093

Pon, G. (2009). Cultural Competency as New Racism: An Ontology of Forgetting. Journal of Progressive Human Services, 20, 59-71. http://dx.doi.org/10.1080/10428230902871173

Rivera, A., Cotto-Escalera, B., Desai, A., Huezo, J., \& Muhammad, D. (2008). Foreclosed: State of the Dream. Boston, MA: United for a Fair Economy.

Rivera, F., \& Erlich, J. (2001). Organizing with People of Color: A Perspective. In J. Tropman, J. Erlich, \& J. Rothman (Eds.), Tactics \& Techniques of Community Intervention (pp. 254-269). Itasca, IL: Peacock Publishers.

Rossiter, A. (2000). The Professional Is Political: An Interpretation of the Problem of the Past in Solution-Focused Therapy. American Journal of Orthopsychiatry, 70, 150-161. http://dx.doi.org/10.1037/h0087656

Schweitzer, D. (2011). Runaway and Homeless Youth: Changing the Discourse by Legitimizing Youth Voice. Portland, OR: Portland State University.

Seijo, R., Gomez, H., \& Freidenberg, J. (1991). Language as a Communication Barrier in Medical Care for Hispanic Patients. Hispanic Journal of Behavioral Sciences, 13, 363-376. http://dx.doi.org/10.1177/07399863910134001

Skrtic, T. M., Sailor, W., \& Gee, K. (1996). Voice, Collaboration, and Inclusion: Democratic Themes in Educational and Social Reform Initiatives. Remedial and Special Education, 17, 142-157. http://dx.doi.org/10.1177/074193259601700304

Song, M. (2014). Challenging a Culture of Racial Equivalence. The British Journal of Sociology, 65, 107-129. http://dx.doi.org/10.1111/1468-4446.12054

Sue, D. (2010). Microaggressions in Everyday Life: Race, Gender and Sexual Orientation. Hoboken, NJ: Wiley.

Takeuchi, T., Sue, S., \& Yeh, M. (1995). Return Rates and Outcomes from Ethnicity-Specific Mental Health Programs in Los Angeles. American Journal of Public Health, 85, 638-643. http://dx.doi.org/10.2105/AJPH.85.5.638

Thomas, J., \& Brunsma, D. (2014). Oh, You're Racist? I’ve Got a Cure for That! Racial and Ethnic Studies, 37, 1467-1485. http://dx.doi.org/10.1080/01419870.2013.783223

Thompson, A. (2008). Resisting the “Lone Hero” Stance. In M. Pollock (Ed.), Everyday Anti-Racism: Getting Real about Race in School (pp. 327-333). New York: The New Press.

US Department of Health \& Human Services (1999). Mental Health: A Report of the Surgeon General. Rockville, MD: US Department of Health and Human Services, Substance Abuse and Mental Health Services Administration, Center for Mental Health Services, National Institutes of Health, National Institute of Mental Health.

US Department of Health \& Human Services (2001). Mental Health: Culture, Race and Ethnicity-A Supplement to Mental Health: A Report of the Surgeon General. Rockville, MD: US Department of Health and Human Services, Substance Abuse and Mental Health Services Administration, Center for Mental Health Services.

US Department of Labor (2009). Labor Force Characteristics by Race and Ethnicity, 2008. Washington DC: Bureau of Labor Statistics.

Uttal, L. (2006). Organizational Cultural Competency: Shifting Programs for Latino Immigrants from a Client-Centered to a Community-Based Orientation. American Journal of Community Psychology, 38, 251-262. http://dx.doi.org/10.1007/s10464-006-9075-y

Walker, R., \& LaDue, R. (1986). An Integrative Approach to American Indian Mental Health. In C. Wilkinson (Ed.), Ethnic Psychiatry (pp. 143-199). New York: Plenum Medical. http://dx.doi.org/10.1007/978-1-4613-2219-1_5

Yamamoto, J., Silva, J., Justice, L., Chang, C., \& Leong, G. (1993). Cross-Cultural Psychotherapy. In A. Gaw (Ed.), Culture, Ethnicity and Mental Illness (pp. 101-124). Washington DC: American Psychiatric Press.

Yeh, M., Takeuchi, T., \& Sue, S. (1994). Asian American Children in the Mental Health System: A Comparison of Parallel and Mainstream Outpatient Service Centers. Journal of Clinical and Child Psychology, 38, 251-262. 
http://dx.doi.org/10.1207/s15374424jccp2301_2

Zeldin, S. (2000). Youth in Decision Making: A Study in the Impact of Youth on Adults and Organizations. Madison, WI: Innovation Center, University of Wisconsin Extension.

http://alaskaice.org/wordpress/wp-content/uploads/2011/08/Youth_in_Decision_Making_Full.pdf 